\title{
Tempos de isolamento social: Infâncias nos encontros virtuais
}

\author{
Bárbara Cecília Marques Abreu'; Magali Oliveira Frassão²
}

Assim, me surpreendo como que é que hoje já é maio, se ontem era fevereiro? (Lispector, 2013: 42).

\begin{abstract}
"Se ontem era fevereiro" e estávamos na escola, nos encontrando diariamente para compartilhar vivências, acolher e vincular crianças, festejar o carnaval, brincar com água para aliviar o calor de um intenso verão, "hoje já é maio". Neste curto espaço de tempo, o mundo passou por inúmeras mudanças que resultaram numa rápida, difícil e isolada organização social, o que exigiu de cada pessoa, em seu canto ao seu modo, inventar e enfrentar medos, desafios.

As escolas foram as primeiras a viver a suspensão de suas atividades e a se ver frente ao inusitado que alterava toda uma organização previamente planejada, conhecida e que nos proporcionava segurança. Frente a uma interrupção abrupta, o calendário escolar, antes com encontros, reuniões, festividades e toda a vida pulsante que acontecia, teve de ser revisto. O caminho seguro que cotidianamente percorríamos encheu-se de pedras e fendas que tinham de ser transponíveis.

Sem crianças brincando, correndo, conversando, investigando, rindo, trocando, chorando, imaginando e vivendo a vida também nas escolas de educação infantil, o que as torna tão dinâmicas e potentes, os espaços foram ficando silenciosos e tristes. Com isso, fomos instadas a inventar e experimentar novas formas de ser docentes e de manter vínculos. Os adultos, agora, isolados em casa, usando máscaras ao sair, sem toque, ou lazer ao ar livre, preocupados com saúde, manutenção do trabalho, administração financeira, e desnorteados em meio às incertezas e aos descasos governamentais, passaram a se dividir no cuidado e na atenção ao(s) filho(s) assumindo as atividades do trabalho a distância, e nos questionando quanto tempo a escola ficaria suspensa.

Em meio a estes acontecimentos, procuramos nos atentar não somente a pensar sobre a pandemia e todas as suas preocupações, a pensar não "exatamente o que acontece, mas alguma coisa no que acontece" (Deleuze, 1974: 152). A pensar as relações, a instituição escolar de educação infantil, e principalmente suas possibilidades de estar presente, mesmo distante socialmente. A atentar-se aos acontecimentos e o que acontece neles, com os bebês e as crianças, suas expressões, sensibilidades, anseios, gostos e desgostos. A nos questionar sobre como os bebês e crianças pequenas sentem e interpretam esta experiência peculiar em suas vidas? Quais estratégias podem ser desenvolvidas para dar protagonismo aos bebês e crianças remotamente?
\end{abstract}

\section{Usando a rede para abastecer a vida}

No contexto educativo escolar no Brasil, especificamente no estado do Rio Grande do Sul, escolas de ensino fundamental e médio, enfrentando inúmeras dificuldades, criaram videoaulas, produziram tarefas e estudos orientados que procuravam assegurar a continuidade do processo de ensino, que foi validado na composição deste ano letivo pelo Conselho Estadual de Educação (2020). Se por um lado, para o ensino fundamental e médio, os encaminhamentos estavam postos, por outro, para a educação infantil os caminhos estavam mais tortuosos.

Algumas escolas de educação infantil atônitas com a situação e preocupadas em se fazer presentes na vida das crianças caíram em armadilhas que deslegitimavam os bebês e crianças, em meio a encaminhamentos que se limitavam a uma tentativa de cumprimento de conteúdos, horas-aula e dias letivos, que tristemente propunham uma educação a distância, nos moldes das demais etapas da educação básica. Enviando inúmeros "trabalhinhos" para pintar e preencher que exigiam materiais comumente escolares e exigiam das crianças que permanecessem sentadas, docili-

\footnotetext{
Pedagoga pela Universidade Federal do Rio Grande do Sul - Brasil. Professora de Berçário da InfânciaS Escola de Educação Infantil -Porto Alegre/ RS, Brasil.

E-mail: barbaracmabreu@gmail.com

2 Pedagoga, Especialista em Educação Infantil e Mestre em Educação pela Universidade Federal do Rio Grande do Sul- Brasil. Diretora e Coordenadora Pedagógica da InfânciaS Escola de Educação Infantil -Porto Alegre/RS, Brasil.

E-mail: mundodac@terra.com.br
} 
zando o corpo para produzir algo distante daquilo que apreciam fazer, constituindo uma espécie de "apostilamento" infantil, andaram, assim, na contramão da legislação vigente, as Diretrizes Curriculares Nacionais para Educação Infantil (DCNEIS, 2013), Base Nacional Comum Curricular (BNCC, 2017), que afirmam as brincadeiras e interações como principais eixos norteadores da proposta escolar da educação infantil.

Neste país tão extenso territorial e culturalmente, o Brasil vivencia diversas formas das crianças viverem suas infâncias e o que aqui se compartilha, não pode ser generalizado como um encaminhamento, mas sim como algo singular vivido por nossa comunidade escolar. A InfânciaS Escola de Educação Infantil, localizada na região central da cidade de Porto Alegre, tem passado seus atuais dias de portas fechadas e com saudades dos aromas, sons, silêncios e agitações de seus dias mais coloridos. A nossa escola, que integra a rede privada de ensino, precisou encontrar estratégias econômicas para se manter, escutando as famílias que a compõem, compreendendo as dificuldades, procurando, sempre que possível, amenizar os impactos deste momento, mas entendendo que algumas perdas seriam inevitáveis para todos.

Nossa equipe, ao longo deste isolamento, vivenciou uma bifurcação, enquanto parte dos funcionários encontram-se suspensos de suas atividades laborais, outra parte, de professor e professoras, busca de suas casas formas e estratégias de fortalecer o vínculo e a escuta com os bebês e as crianças, através de encontros virtuais, procurando dar conta de algumas questões: Como continuar mantendo vínculos com bebês e crianças, defendendo uma proposta brincante e interativa que envolva toda a família? Como contar com o auxílio do adulto para fazer chegar o que é produzido e para compartilhar o que os bebês e crianças produzem, inventam, imaginam, desejam? E mais ainda, se o que torna possível grande parte do trabalho pedagógico na escola se sustenta a partir das expressões, falas, gestos, desejos, concordância, oposição do que dizem as crianças, como fazer quando existe o impedimento das interações e trocas face a face?

Ao iniciarmos o ano, preocupadas, acompanhávamos a propagação e os efeitos da COVID-19 na China e em alguns países europeus. Sabíamos que, em breve, viveríamos a pandemia. Não tardou a chegar o Decreto Municipal $\mathrm{n}^{\circ}$ 20.502, de 17 de março de 2020 determinando a suspensão do trabalho escolar. Já havíamos elegido nos comunicar por e-mail com as famílias e crianças, sugerindo brincadeiras, canções, receitas e, neste momento, produzimos leituras e contação de histórias e disponibilizamos links para serem acessados no YouTube. Todavia, percebemos a formalidade, o distanciamento e a impossibilidade de saber como as crianças estavam fazendo uso do que enviávamos por e-mail. Após avaliarmos que este canal não estava funcionando como desejávamos, buscamos outro.

Apesar da forte incidência do uso de smartfones pelas crianças, que vivem uma realidade econômica e social privilegiada, onde é possível ter acesso a determinados bens, defendíamos que bebês não fizessem uso de tecnologia e que, ao usá-las, as crianças o fizessem ocasionalmente e sob supervisão de uma pessoa adulta. Entretanto, como nada é definitivo e fixo frente à pandemia, estamos a cada dia nos reinventando enquanto escola, nossas certezas começaram a resvalar e nos vemos organizando encontros virtuais e buscando manter vinculações fazendo uso daquilo que tanto criticávamos e que Lévy (1993) propõe como sendo ecologia cognitiva. A pandemia exigiu colocarmos em suspensão algumas certezas e inventarmos uma prática fazendo uso das mídias eletrônicas para mantermos proximidade com cada criança em sua casa. Tivemos muitas dificuldades já que não era usual e tateávamos no uso de algumas técnicas, pensando em como produzir materiais que dialogassem com a primeira infância. Talvez, a partir destas circunstâncias, estejamos forjando uma nova forma de relação.

No início de abril, com a anuência de quase todas as famílias criamos cinco grupos no WhatsApp. E, com os grupos formados, todos foram convidados a criar, sugerir, olhar, contar e compartilhar: brincadeiras, histórias, recados, silêncio, saudade, tristeza, alegria, desejo, enfim, falar de si e nos provocar a produzir ou sugerir algo para nos aproximar e tornar menos doloroso e mais leve viver este tempo. O intuito era que tanto a família, a criança, o bebê quanto à equipe produziriam como consumiriam cultura com cara de criança e infância(S). As famílias aqui desempenham um papel essencial, pois precisam auxiliar os pequenos, na produção e no compartilhamento do que desejam enviar. A tecnologia passou a assumir um lugar que funde experiências vividas em casa, que eram impulsionadas por sugestões da escola, mas que também tinham uma independência absoluta.

De nossa parte, sugerimos filmes, musicais e vídeos de contação de histórias, assim como escolhemos algumas narrativas de histórias que foram postadas tanto em vídeo, como áudio. Percebemos que fez todo o sentido para os bebês e as crianças pequenas o vídeo no qual a professora está tão visível como o livro a ser lido ou contado. As canções e músicas, do cancioneiro popular brasileiro, que era explorado na escola, foram igualmente importantes e apreciadas por bebês e crianças que dançavam, batiam palmas e acompanhavam numa visível alegria. Nosso professor de música chamou para lhe auxiliar, em alguns vídeos, um fantoche de uma simpática bruxinha, que caiu na graça das crianças. Várias receitas postadas em vídeo pela nutricionista, na companhia de um fantoche de cãozinho, foram apreciadas e produzidas pelas crianças. Brincadeiras sugeridas pela professora de Expressão Corporal serviram de inspiração para a criação de outras brincadeiras, numa ciranda que mostra que nada é igual e que a imaginação deve ser educada.

Pensar propostas brincantes, interativas e que fizessem sentido às crianças foi um grande desafio. Nossas professoras estiveram disponíveis para pensar, refletir, estudar e trocar, sem pedagogizar o ambiente familiar. Tínhamos a preocupação de nutrir os grupos com o que era construído na e pela família, legitimando o compartilhamento, mas nos pareceu, em dado momento, que isso era desnecessário. As crianças pareciam saber e valorizar aquilo que por elas era pensado. Nosso papel nesse sentido era reconhecer e não deixar passar em branco as postagens. 
Nesta trama de relações virtuais, de uma forma tranquila, sem atropelos ou avalanches de informações e produções, fomos nos encantando com as brincadeiras, os fazeres e as interações, pois "a formação de uma rede cria uma espécie de fora que permite ao humano sobreviver" (Deligny, 2018:18). Passamos a visualizar bebês compenetrados e atentos lavando louça, pensando estratégias e impondo força para puxar o cesto das roupas, auxiliando nos afazeres domésticos. Barulhando com diferentes objetos e produzindo sons com instrumentos musicais. Brincando com baldes, bacias, potes. Atentos às ilustrações de livros ou outras imagens, inventando narrativas nas quais ouvíamos os nomes dos outros bebês que estavam na memória e representados nos bonecos e bonecas. Se expressando com gritos e risos ao visualizarem vídeos das ações de outros bebês de seu grupo, que manifestavam para nós a expressão de seus sentimentos, de saudade.

Crianças explorando livros, inventando e recontando narrativas: porquinhos de legos, sucatas e papéis que corriam de um lobo bravo tentando se esconder. Crianças brincando e usando a imaginação e, mais que isso, umas ensinando às outras o poder da criação. Crianças na cozinha mexendo, experimentando, observando e participando ativa e alegremente do fazer de um alimento junto com familiares. Rindo, conversando, se espantando e deixando escorrer alegria ao verem os vídeos umas das outras. Crianças se encantando com a troca de brincadeiras, com a sugestão de atividades físicas. Mães e pais postando vivências com filhos e filhas e procurando achar o melhor jeito de incluir as crianças nas atividades do trabalho.

Presenciamos os dentes de leite ficaram frouxos e caírem. Rito social para o qual foi preciso achar uma poesia que desse conta das tantas "porteirinhas", que eram exibidas e recebiam muitas mensagens em vídeo, áudio e emojis, pois "O sorriso mais sincero é o sorriso desdentado" (Quintana, 2005: 33). Esses momentos, segundo algumas crianças, dariam muito trabalho à fada do dente. Soubemos que algumas crianças cultivam horta em casa. Conhecemos a sala, o quarto, o pátio, os brinquedos e alguns hábitos alimentares. Algumas crianças exibiam os seus bichinhos de estimação e ficamos espantadas com o número de felinos que fazem parte da vida das crianças nesta comunidade escolar.

Durante este tempo de isolamento, a Páscoa agitou as postagens dos grupos, e foi compartilhada com alegria pelas crianças, que postavam desenhos, bilhetes, recados para o Coelho da Páscoa, pintura de casquinhas e, por fim, exibiam os seus ninhos. Outro momento especial, que precisou ser reinventado, foi e é a comemoração dos aniversários das crianças. Partiu de uma família a ideia de usar outra plataforma digital na qual fosse possível reunir todas as crianças do grupo ao mesmo tempo em vídeo, para tentar dar conta do significado desta data. Nas diferentes faixas etárias, foi um transbordamento de alegria, de gritos quando as crianças se viam. O encontro era e é rápido, mas extremamente festivo e significativo.

\section{Nada substitui encontros face a face}

Seguimos nos encontrando virtualmente, procurando reinventar a escola, para viver este tempo histórico tão inesperado. Percebemos que, em alguns momentos, paira um silêncio absoluto nos grupos criados, o que por vezes nos inquieta e nos mobiliza a lançar uma pergunta para lembrar que estamos por perto. Buscamos, aqui, compartilhar nossas experiências, nossos questionamentos e algumas respostas provisórias e, embora estejamos avaliando como positivos os encontros virtuais, nada substitui estarmos na escola, pois por mais inventivas que sejam as estratégias, vivemos a impossibilidade dos encontros físicos, e os bebês e crianças sentem isso, se incomodam e questionam quando poderão rever seus pares.

Encontramo-nos, tanto adultos quanto crianças e bebês, com saudade: dos cheiros, das invenções, das trocas, dos desafios, das conversas, dos sorrisos, dos gritos, da companhia, da inteligência, da sensibilidade, da amorosidade, da paixão, das disputas, das negociações, dos abraços, dos chamegos vividos por toda a comunidade escolar. Saudade daquilo que Larrosa (2017) aponta como experiência, que nos passava, acontecia, formava e transformava na relação com bebês e crianças. Assim, nos pegamos surpresas com o fato de que tão logo tenha começado o ano, com o retorno das crianças em fevereiro, e hoje já estamos em maio, vivendo um isolamento social e transformando o espaço virtual como uma possibilidade de encontros.

\section{Referências bibliográficas}

Brasil. (2013). Ministério da Educação. Diretrizes Curriculares Nacionais Gerais da Educação Básica / Ministério da Educação. Secretaria de Educação Básica. Diretoria de Currículos e Educação Integral. Brasília: MEC, SEB, DICEI (en línea). http:// portal.mec.gov.br/index.php?option=com_docman\&view=download\&alias=15548-d-c-n-educacao-basica-nova-pdf\&Itemid=30192, acesso 6 de maio de 2020 .

Brasil. (2017). Ministério da Educação. Base Nacional Comum Curricular - BNCC, versão aprovada pelo CNE, novembro de 2017 (en línea). http://basenacionalcomum.mec.gov.br/a-base, acesso 6 de maio de 2020.

Brasil. (2020). Prefeitura de Porto Alegre. Decreto $N^{\circ}$ 20.502, de 17 de março de 2020. Dispõe sobre medidas a serem adotadas para o enfrentamento da emergência de saúde pública decorrente do novo Coronavírus (COVID-19) no Município de Porto Alegre (en línea). https://leismunicipais.com.br/a/rs/p/porto-alegre/decreto/2020/2050/20502/decreto-n-20502-2020-inclui-os-incs-iii-e-iv-no-art-1-e-revoga-o-art-2-do-decreto-n-20499-de-16-de-marco-de-2020-que-dispoe-sobre-medidas-a-serem- 
-adotadas-para-o-enfrentamento-da-emergencia-de-saude-publica-decorrente-do-novo-coronavirus-covid-19-no-municipio-de-porto-alegre, acesso 7 de maio de 2020.

Brasil. (2020). Concelho Estadual de Educação/ RS. Parecer CEED n ${ }^{\circ}$, de 18 de março de 2020. Orientações para as atividades escolares durante medidas de prevenção ao novo Coronavírus - COVID-19 (en línea). http://www.ceed.rs.gov.br/conteudo/23221/parecer-ceed-n\%c2\%ba-1\%2c-de-18-de-marco-de-2020, acesso 6 de maio de 2020.

Deleuze, G. (1974). A Lógica do Sentido; tradução de Luiz Roberto Salinas Fortes. São Paulo: Perspectiva, Ed. da Universidade de São Paulo.

Deligny, F. (2018). O Aracniano e outros textos. $2^{\mathrm{a}}$. ed. São Paulo: n-1edições.

Quintana, M. (2005). Lili inventa o mundo. $9^{\mathrm{a}}$ ed. São Paulo: Ed. Global.

Larrosa, J. (2017). Tremores: escritos sobre experiência. $1^{\mathrm{a}}$ ed. Belo Horizonte: Ed. Autêntica.

Lévy, P. (1993). As tecnologias da inteligência: o futuro do pensamento na era da informática. $1^{\text {a }}$ ed. Rio de Janeiro: Ed. 34.

Lispector, C. (2013). As palavras / Curadoria de Roberto Corrêa dos Santos. 1ª. ed. Rio de Janeiro: Rocco. 